\title{
Banana Rachis CNC/Clay Composite Filter for Dye and Heavy Metals Adsorption from Industrial Wastewater
}

\author{
Md. Monjurul Islam, Md. Shafiqul Islam, Mohd. Maniruzzaman, Md. Minhaz-Uı Haque ${ }^{*}$, Anika \\ Amir Mohana
}

Department of Applied Chemistry and Chemical Engineering, Islamic University, Kushtia 7003, Bangladesh Email:minhaz1978@gmail.com

Received: 10 March 2021; Revised: 18 May 2021; Accepted: 19 May 2021

\begin{abstract}
This study demonstrates a successful processing and utilization of banana rachis cellulose nanocrystals (CNCs) dispersed clay composite filter which is capable of adsorbing dye and heavy metal ions namely $\mathrm{Pb}(\mathrm{II})$ and $\mathrm{Cr}$ (III) from industrial wastewater. The composite of different compositions was prepared by dispersing the cellulose nanocrystals, obtained by acid hydrolysis of banana rachis fibres, within the tri-ethyl amine treated clay. The CNC and treated clay were characterized by Fourier transform infrared (FTIR), X-ray diffractometry (XRD), and scanning electron microscopy (SEM) analyses. Industrial wastewater containing a basic yellow2 dye and two heavy metal ions, $\mathrm{Pb}(\mathrm{II})$ and $\mathrm{Cr}(\mathrm{III})$, was passed through the prepared filters set in a column. The dye and metal ions adsorption capability of the filters were analyzed by determining the dye and metal ions concentration into the water before and after passing through the composite filter. The concentration of dye and metal ions in water was determined by a UV-visible spectrophotometer and an atomic absorption spectrophotometer, respectively. It was found that the dye adsorption capacity of the composite filters was about $50 \mathrm{mg}$ per gram of composite as well as $\mathrm{Pb}(\mathrm{II})$ and $\mathrm{Cr}(\mathrm{III})$ ions adsorption capacities of the composite filters were $>10.0 \mathrm{mg}$ and $>12.4 \mathrm{mg}$ respectively per gram of the composite when CNC content in the composite was $>30 \mathrm{wt} . \%$. It was also found that the metal ions adsorption capability of the composite filter was improved with increasing $\mathrm{CNC}$ content in the composites.
\end{abstract}

Keywords: banana rachis fibre, clay, heavy metals, nanocellulose, wastewater

\section{Introduction}

Industrial wastewater, due to the presence of heavy metals and synthetic dyes which are responsible for environmental pollution, has a very adverse effect on the environment. Heavy metal ions, particularly lead and chromium present in industrial wastewater are very toxic [1]-[4]. These heavy metal ions can also affect human health such as dermatitis, bronchial carcinomas, brain damage, etc. [5]-[6]. Dyes present in industrial wastewater, mainly contributed by textile industries [7], are also toxic and have a serious effect on the environment [8].

Considering those adverse effects of heavy metals and dyes on the environment, many researchers have developed different materials for removing dyes and heavy metals from industrial wastewater [9]-[15]. Clays and clay-

Copyright (C2021 Md. Minhaz-Ul Haque, et al.

DOI: https://doi.org/10.37256/est.222021817

This is an open-access article distributed under a CC BY license

(Creative Commons Attribution 4.0 International License)

https://creativecommons.org/licenses/by/4.0/ 
based materials, because of high capability and mechanical stability, are used to adsorb heavy metals and dyes from wastewater [13]-[15]. Clays have different varieties. However, the most common are montmorillonite, and kaolinite [16], [17]. The clay used in this study, Bijoypur clay, is a kind of kaolinite clay, which contains $\mathrm{SiO}_{2}(70.08 \%), \mathrm{Al}_{2} \mathrm{O}_{3}(27.24 \%)$, $\mathrm{Fe}_{2} \mathrm{O}_{3}(1.03 \%)$, and $\mathrm{TiO}_{2}(1.65 \%)$ [18]. The chemical formula of kaolinite is $\mathrm{Al}_{2} \mathrm{Si}_{2} \mathrm{O}_{5}(\mathrm{OH})_{4}$. It is an aluminosilicate clay and its basic structure contains silicate sheets. The layered structure is made up of a tetrahedral sheet of Si-O and an octahedral layer of Al-O [19], [20].

At present, different biodegradable polymers such as cellulose [21], [22], chitosan [23], Jalshakti [24], poly(vinyl alcohol) [25], etc. based materials are also being used for removing dyes and heavy metals from wastewater making composites. Among them, cellulose is a universal and sustainable polymer present in nature as a basic material of plants. The yearly biomass generation of cellulose is around one trillion tonnes, which suggests the limitless use of cellulose as a natural polymer raw material. Conversion of micro-cellulose materials into nanocellulose results in an intense increment of the accessible surface area. Nanocellulose and nanocellulose based composite filters and membranes have been appeared to adsorb metal ions and metals [26]-[31] as well as dyes [32]-[34] from water solution.

The banana rachis is a waste of banana cultivation. It contains a significant amount of lignocellulosic fibres. The use of banana rachis fibres for textile and other purposes as a natural material is a new concept in Bangladesh. The fibres have not been exploited much commercially yet, as it was considered inferior to abaca and other available hard fibres. It can be extracted by hand scraping, retting or using machines, and it can also be chemically extracted. Nanocellulose can be prepared by acid hydrolysis of $\alpha$-cellulose obtained from the banana rachis fibres by traditional bleaching and alkali treatment. Hence, this study aimed to make a biodegradable composite filter based on clay and CNC obtained from banana rachis by a simple mixing method to remove the dye and two hazardous heavy metals such as lead and chromium from industrial wastewater as well as to investigate the performance of the fabricated composite filter.

\section{Experimental}

\subsection{Materials}

Banana (Musa acuminata L) rachis fibres (Figure 1) were obtained from the banana rachis, which was collected from rural area Modhupur, a place of Kushtia, in Bangladesh. Kaolinite clay (Figure 2a) was collected from Bijoypur of Netrokona district in Bangladesh. Industrial wastewater was collected from Kumarkhali, Kushtia, Bangladesh. It contained heavy metal ions $\mathrm{Pb}(\mathrm{II})$ and $\mathrm{Cr}(\mathrm{III})$ as well as a basic yellow2 dye. The chemicals used in this study, such as sodium hydroxide $(\mathrm{NaOH})$, sulphuric acid $\left(\mathrm{H}_{2} \mathrm{SO}_{4}\right)$, sodium acetate $\left(\mathrm{CH}_{3} \mathrm{COONa}\right)$, acetic acid $\left(\mathrm{CH}_{3} \mathrm{COOH}\right)$, sodium chlorite $\left(\mathrm{NaClO}_{2}\right)$, and tri-ethyl aniline $\left(\left(\mathrm{C}_{2} \mathrm{H}_{5}\right)_{3} \mathrm{~N}\right)$, were analytical grade and purchased from British Drug Houses $(\mathrm{BDH})$, England.

\subsection{Methods}

\subsubsection{Preparation of cellulose nano-crystal (CNC) from banana rachis fibres}

Banana rachis fibres were extracted from banana rachis by retting process. The banana rachis was cut about one foot and put into normal water in a container for two weeks. Thereafter, fibres were separated and washed with fresh water several times and finally dried and store in a polybag. The dried fibres were then bleached with $1 \% \mathrm{NaClO}_{2}(1$ g fibres: $80 \mathrm{ml} \mathrm{NaClO}$ ) solution at $90-95^{\circ} \mathrm{C}$ temperature and $\mathrm{pH} 4$ for 90 minutes with constant stirring. The $\mathrm{pH}$ of the liquor was maintained using acetic acid and sodium acetate buffer solution $(1 \mathrm{ml}$ buffer solution: $10 \mathrm{ml}$ chlorite solution) to ensure the proper bleaching of the fibres.

The bleached fibres were then treated with $17.5 \mathrm{wt} . \% \mathrm{NaOH}$ solution to obtain $\alpha$-cellulose by removing hemicellulose [35], [36]. The $\alpha$-cellulose fibres were then hydrolyzed by $60 \mathrm{wt} . \%$ sulphuric acid solution [37] at $45^{\circ} \mathrm{C}$ for 45 minutes ( $50 \mathrm{ml}$ acid solution/ $1 \mathrm{~g}$ of $\alpha$-cellulose) as shown in Figure $1 \mathrm{~b}$. After hydrolysis, the nanocrystals were washed with distilled water by centrifugation at $10000 \mathrm{rpm}$ to remove free acid. Washing of crystals by centrifugation process was repeated 5 times. Finally, $\mathrm{CNC}$ was collected from the vial of a centrifuge and preserved in ethanol. 

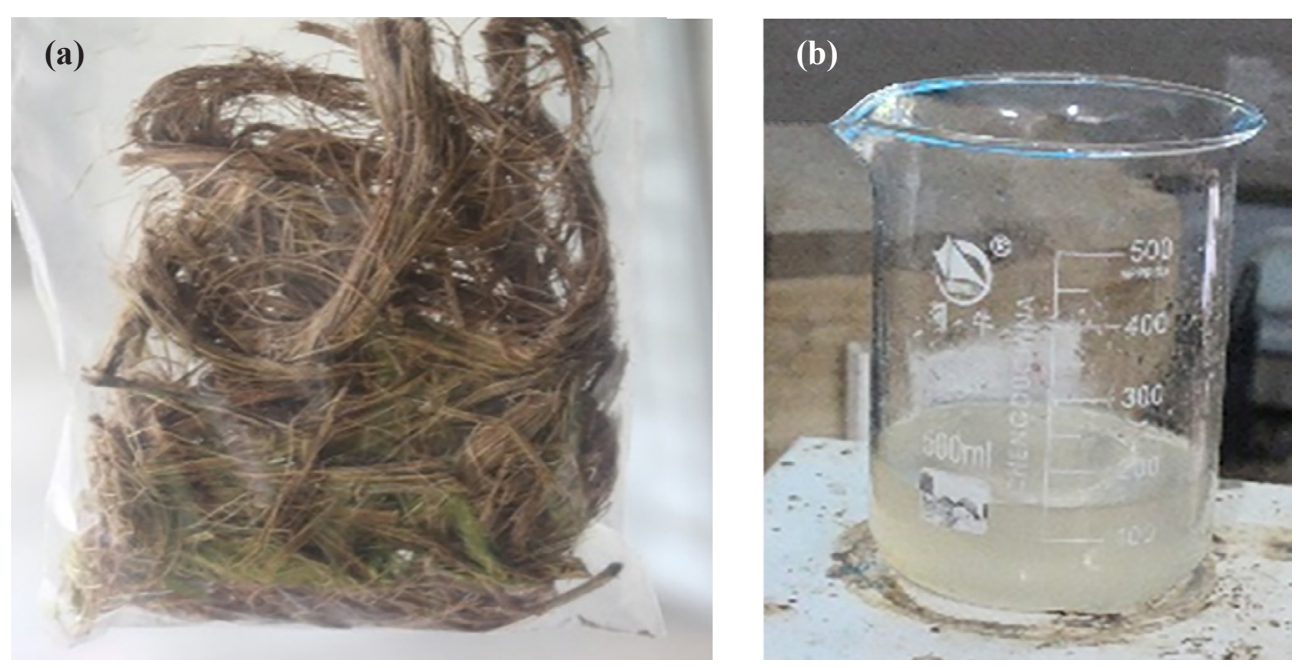

Figure 1. Photographs of (a) banana rachis fibres, and (b) $\mathrm{CNC}$ suspension

\subsubsection{Treatment of clay}

Clay collected from Bijoypur was treated with 5\% tri-ethyl amine $\left[\left(\mathrm{CH}_{3}\right)_{3} \mathrm{~N}\right]$ for 3 hours for removing organic materials and increasing the hydrophobicity of clay. The $\mathrm{pH}$ of the solution was maintained between 11.8-11.4 during treatment of the clay [38]. After treatment, the clay was filtered and dried at a temperature of $105^{\circ} \mathrm{C}$ temperature. Figure $2 \mathrm{~b}$ shows a photograph of treated clay.
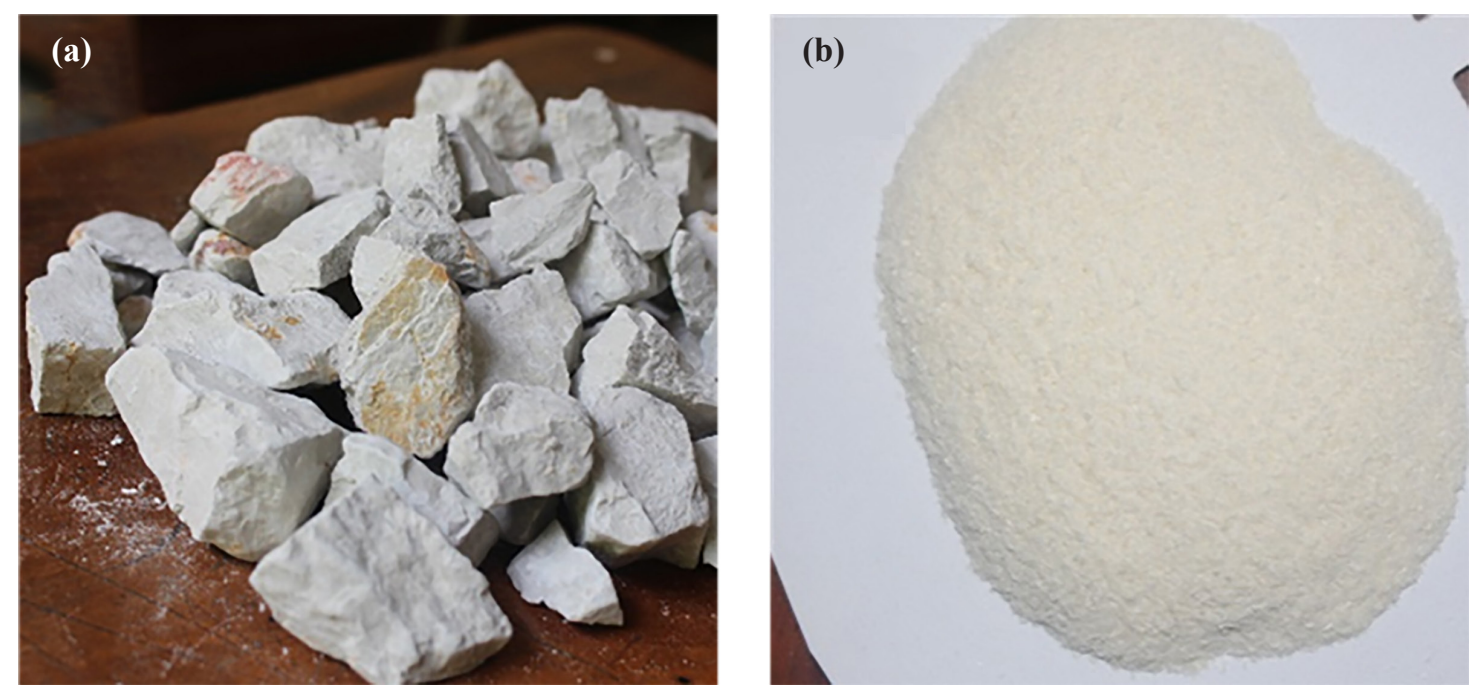

Figure 2. Photographs of (a) clay and (b) treated clay

\subsubsection{Preparation of composite and column}

CNC dispersed clay composite filter was prepared by simple blending method. CNCs were blended with the treated clay in a mortar by a spatula which was then soaked into ethanol. Composite filters of $5 \mathrm{~g}$ of different clay/CNC compositions 90/10, 80/20, 70/30, and 60/40 as reported in Table 1 were prepared for investigating their performance. A filter of plain clay was also made and used as a control. At first, a $0.5 \mathrm{~cm}$ cotton bed was placed at the bottom of a filter column having $1 \mathrm{~cm}$ diameter and $80 \mathrm{~cm}$ length as shown in Figure 3. Then a sand bed of $0.5 \mathrm{~cm}$ thickness was 
prepared. After completing the preparation of the sand bed the clay/CNC composite was placed into the column. The thickness of the nanocomposite filter layer was $2 \mathrm{~cm}$.

Table 1. Compositions of fabricated nanocomposites

\begin{tabular}{ccc}
\hline Sample & Wt.\% of clay & Wt.\% of CNC \\
\hline Composite filter 1 & 100 & 0 \\
Composite filter 2 & 90 & 10 \\
Composite filter 3 & 80 & 20 \\
Composite filter 4 & 70 & 30 \\
Composite filter 5 & 60 & 40 \\
\hline
\end{tabular}

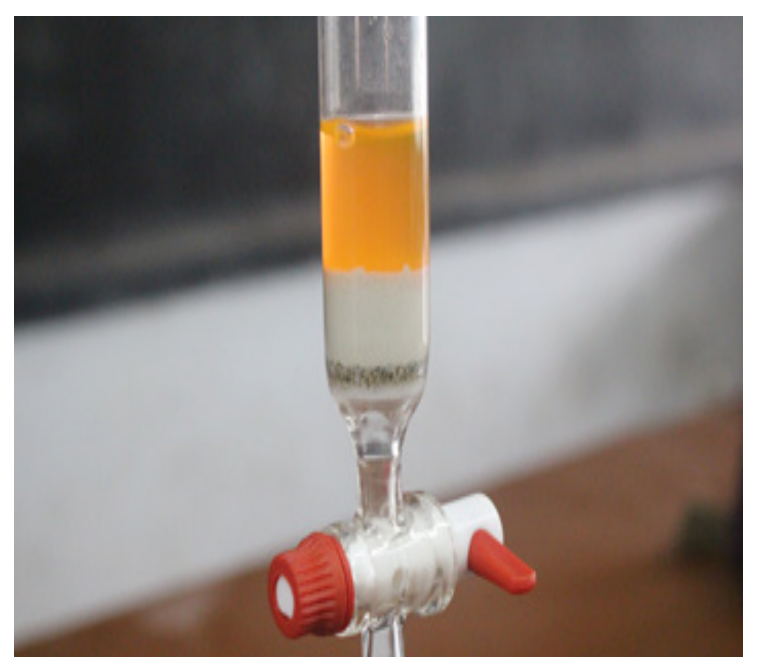

Figure 3. A column with a composite filter and dye solution

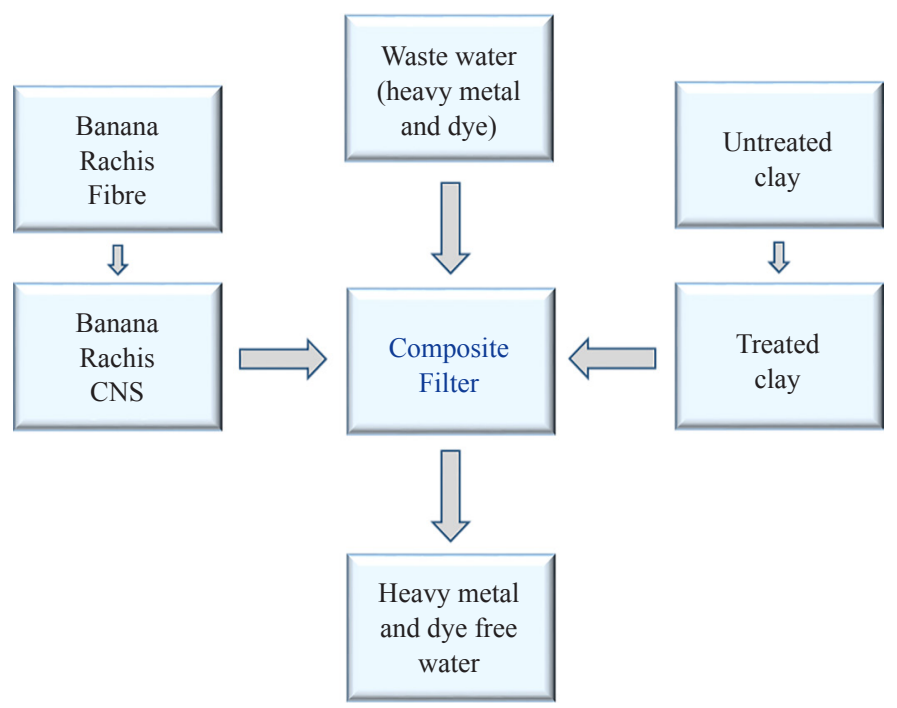

Figure 4. The flow diagram shows fabrication and waste-water purification 
The thickness of the composite layer was very important. If the thickness exceeded that limit then it would take a long time to pass the water through the filter layer, whereas if the layer was lower than the desired scale then the filter layer would lose the resistance properties and allow to pass all the dye molecule through it. The composites preparation and wastewater purification process are also shown in a flow diagram of Figure 4.

\subsection{Characterization techniques}

\subsubsection{Fourier transform infrared (FTIR) spectroscopy}

Chemical modification of clay, as well as available functional groups present in clay and CNC, were investigated by FTIR spectroscopy using ATR-FTIR (Attenuated Total Reflectance/Fourier Transforms Infrared) spectrophotometer (Model-FTIR8400S spectrophotometer, SHIMADZU Corp, Japan) to functional group detection. The samples were scanned in the frequency range $500-4000 \mathrm{~cm}^{-1}$ at a resolution of $4 \mathrm{~cm}^{-1}$.

\subsubsection{X-ray diffraction (XRD) spectroscopy}

XRD analysis of $\alpha$-cellulose, CNC, untreated and treated clay was carried out by a Rigaku Ultima IV diffractometer operating at $40 \mathrm{kV}$ and $30 \mathrm{~mA}$, using the radiation $(\lambda=0.1546 \mathrm{~nm})$. The crystalline degree of the samples was determined as the ratio of the areas of crystalline reflections to the whole area (after subtraction of background) in the $2 \theta$ range. The XRD method is based on Bragg's Law [39]: $n \lambda=2 d \sin \theta$.

\subsubsection{Scanning electron microscopy (SEM)}

SEM images of treated and untreated clay were taken at $20 \mathrm{kV}$ by a Scanning Electron Microscope, JSM-6490LA, Jeol, Japan. The surface morphology of the treated and untreated clay was investigated from the SEM images.

\subsubsection{UV spectroscopy}

UV spectroscopy was used to determine the concentration of dye in wastewater and purified water. UV spectroscopy obeys the Beer-Lambert law. The analysis was carried out on UV-1601. The wavelength was fixed at 520 nm.

\subsubsection{Atomic absorption spectroscopy (AAS)}

AAS was used to determine the heavy metal ions (lead and chromium) concentration in wastewater and purified water. The atomizer in which the analyte was atomized was a flame type. For the identification of heavy metal, Varian AA 240 FS atomic absorption spectrophotometer was utilized. The efficiency of banana rachis CNC and clay composite for $\mathrm{Pb}(\mathrm{II})$ and $\mathrm{Cr}(\mathrm{III})$ ions removal from aqueous solutions was calculated quantitatively by using the following equation:

$$
\text { Removal efficiency }(\%)=\frac{C_{i}-C_{f}}{C_{i}} 100
$$

Where $C_{i}$ is the initial metal ion concentration $(\mathrm{mg} / \mathrm{L}), C_{f}$ is the final (residual) metal ion concentration $(\mathrm{mg} / \mathrm{L})$. All the determinations of $\mathrm{Pb}(\mathrm{II})$ and $\mathrm{Cr}(\mathrm{III})$ ions in the solutions were carried out in triplicates and the average values were reported.

\section{Results and discussion}

\subsection{FTIR analysis of cellulose nanocrystals and clay}

FTIR analysis was carried out to investigate various functional groups of fibres and clay. Figure 5 represents the 
FTIR spectrum of CNC. In the spectrum of Figure 5, it can be seen that a broad absorption band in the region 3600$3200 \mathrm{~cm}^{-1}$ corresponds to the characteristic $-\mathrm{OH}$ stretching vibration and hydrogen bond of the hydroxyl groups of cellulose. The peaks at $2943-2856 \mathrm{~cm}^{-1}$ are assigned to the $\mathrm{C}-\mathrm{H}$ stretching vibration from the $-\mathrm{CH}_{2}$ group of cellulose. The strongest bands in the spectrum at 1103 and $1051 \mathrm{~cm}^{-1}$ are assigned to $-\mathrm{CO}$ stretching for secondary alcohol [40], [41].

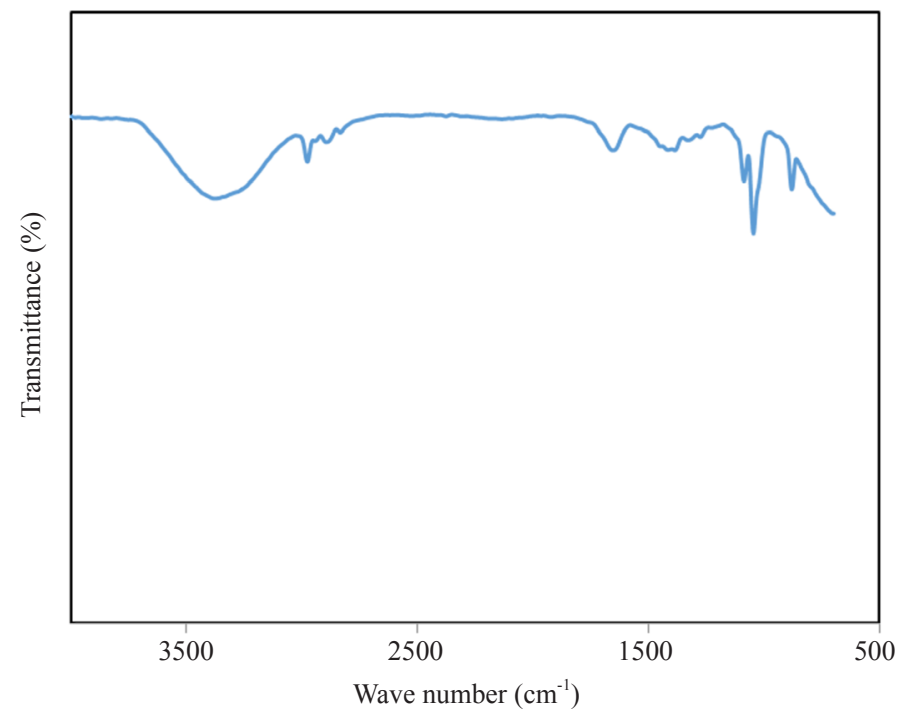

Figure 5. FTIR spectrum of cellulose nanocrystals

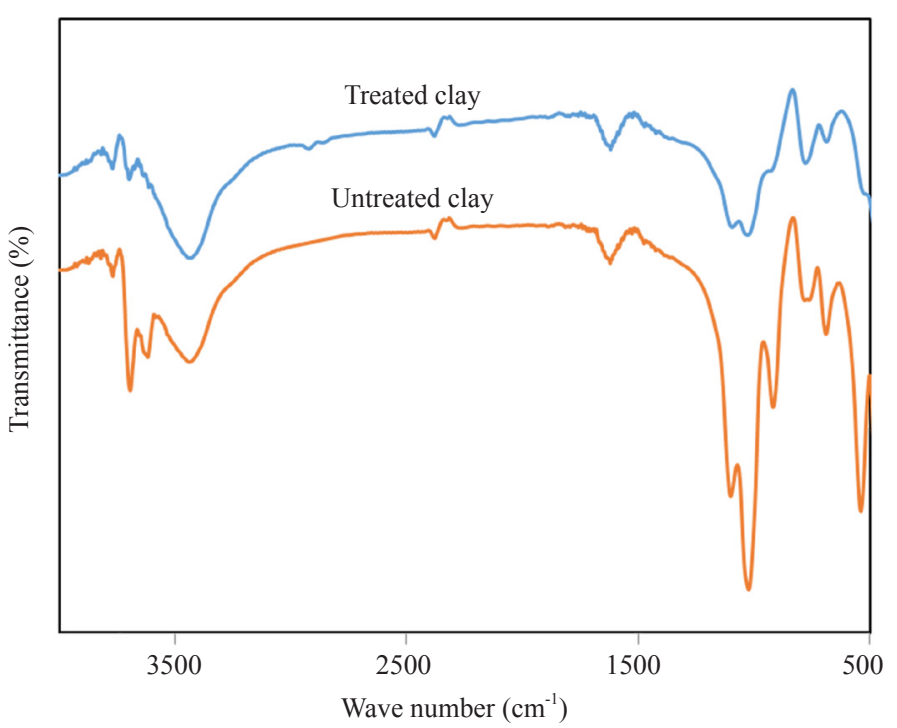

Figure 6. FTIR spectra of treated clay and untreated clay

FTIR analysis of untreated clay and treated clay was carried out to investigate the available functional groups in clay as well as to see the evidence of tri-ethyl amine onto the treated clay. Figure 6 represents the FTIR spectra of untreated and treated clay. The peak assigned to water $-\mathrm{OH}$ stretching is found at $3441 \mathrm{~cm}^{-1}$ [42]. The most important mineral peaks are observed at 1101 and $1024 \mathrm{~cm}^{-1}$ due to $\mathrm{Si}-\mathrm{O}$ stretching modes. At $918 \mathrm{~cm}^{-1}$, the peak is due to the 
presence of bending Al-O-H bonds. The bending due to the presence of water is observed at $1622 \mathrm{~cm}^{-1}$. The strong peak at $783 \mathrm{~cm}^{-1}$ is due to free silica and/or quartz. Some other peaks that can be observed in the fingerprint region but heavily overlapped are at $690 \mathrm{~cm}^{-1}$ for Si-O stretching and $540 \mathrm{~cm}^{-1}$ for Si-O-Al bending. All these peaks confirm the presence of kaolinite [43]-[46]. The presence of C-H (alkane) peaks at about $2900 \mathrm{~cm}^{-1}$ in the spectrum of treated clay indicated the incorporation of ethyl group into the clay, as two carbon-containing ethyl group, an alkane, gives a stretching peak at 2800-3000 $\mathrm{cm}^{-1}$ corresponding to the $\mathrm{sp}^{3}$ hybridization peaks of alkanes. The presence of primary amine from the triethyl amine used for modification gives a narrow band at $3400 \mathrm{~cm}^{-1}$ and also at $1600 \mathrm{~cm}^{-1}$ [47].

\subsection{X-ray diffraction (XDR) analysis of CNC and clay}

$\mathrm{XRD}$ analysis of $\mathrm{CNC}$ and clay was carried out to evaluate the crystalline nature of banana rachis cellulose and $\mathrm{CNC}$ as well as to investigate the crystal structure of chemically modified clay. Figure 7a represents XRD spectra of $\alpha$-cellulose and $\mathrm{CNC}$ of the banana rachis. In Figure $7 \mathrm{a}$, it can be seen that each spectrum has common crystalline peaks located at $15.7^{\circ}, 22.4^{\circ}$ and $31^{\circ}$ in $2 \theta$ scale corresponding to the (101) (002) and (040) crystallographic plane, respectively [48], [49]. Both $\alpha$-cellulose and CNC exhibit the characteristic peak of cellulose-I (the crystal form of native cellulose) [50] that can be ascribed to the fact that the crystal structure of cellulose was not changed after acid hydrolysis.
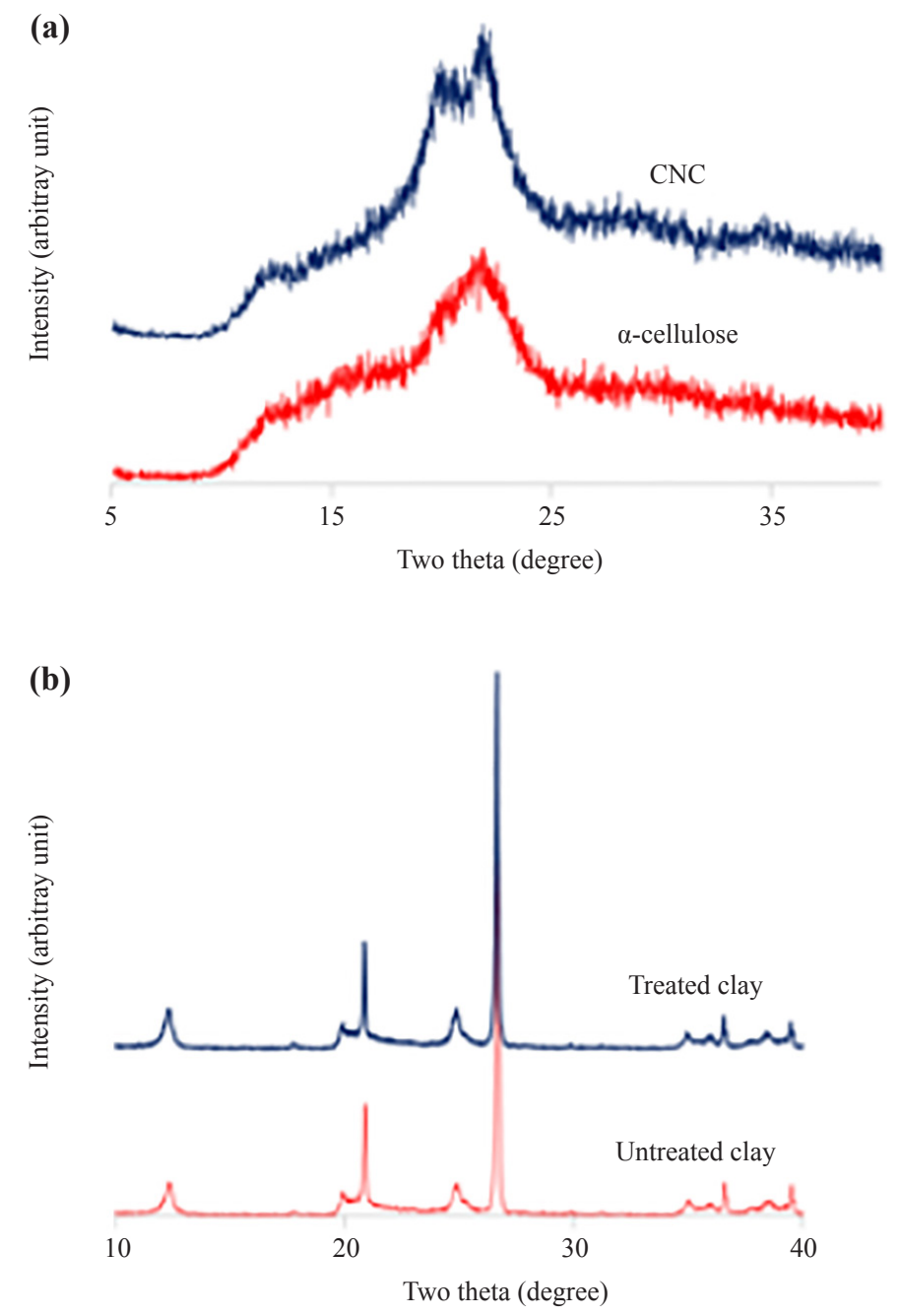

Figure 7. XRD pattern of (a) fibres and (b) clays 
In the spectra of $\alpha$-cellulose and $\mathrm{CNC}$, it can also be noticed that the removal of large amounts of amorphous parts by acid hydrolysis made the crystalline peaks sharper and more defined in the spectrum of CNC than that of $\alpha$-cellulose that indicates increasing crystallinity in CNC. Hence, the XRD analysis of banana rachis cellulose and CNC indicated that the crystal structure in CNC was not changed. However, crystallinity was increased in CNC due to the removal of non-crystalline parts by acid hydrolysis. Figure $7 \mathrm{~b}$ represents XRD spectra of chemically treated and untreated clay. In Figure $7 \mathrm{~b}$, it can be seen that the major diffraction angles $(2 \theta)$ for kaolinite, chemical composition $\mathrm{Al}_{2} \mathrm{Si}_{2} \mathrm{O}_{5}(\mathrm{OH})_{4}$, are $12.37^{\circ}$ and $24.85^{\circ}$ and for quartz are $20.82^{\circ}$ and $26.67^{\circ}$ [18], [51]. The peaks related to the different planes of crystal of untreated clay and treated clay are similar that indicates that the crystal structure of clay was not changed after treatment with tri-ethyl amine.

\subsection{Surface morphology of treated clay, untreated clay, and composite}
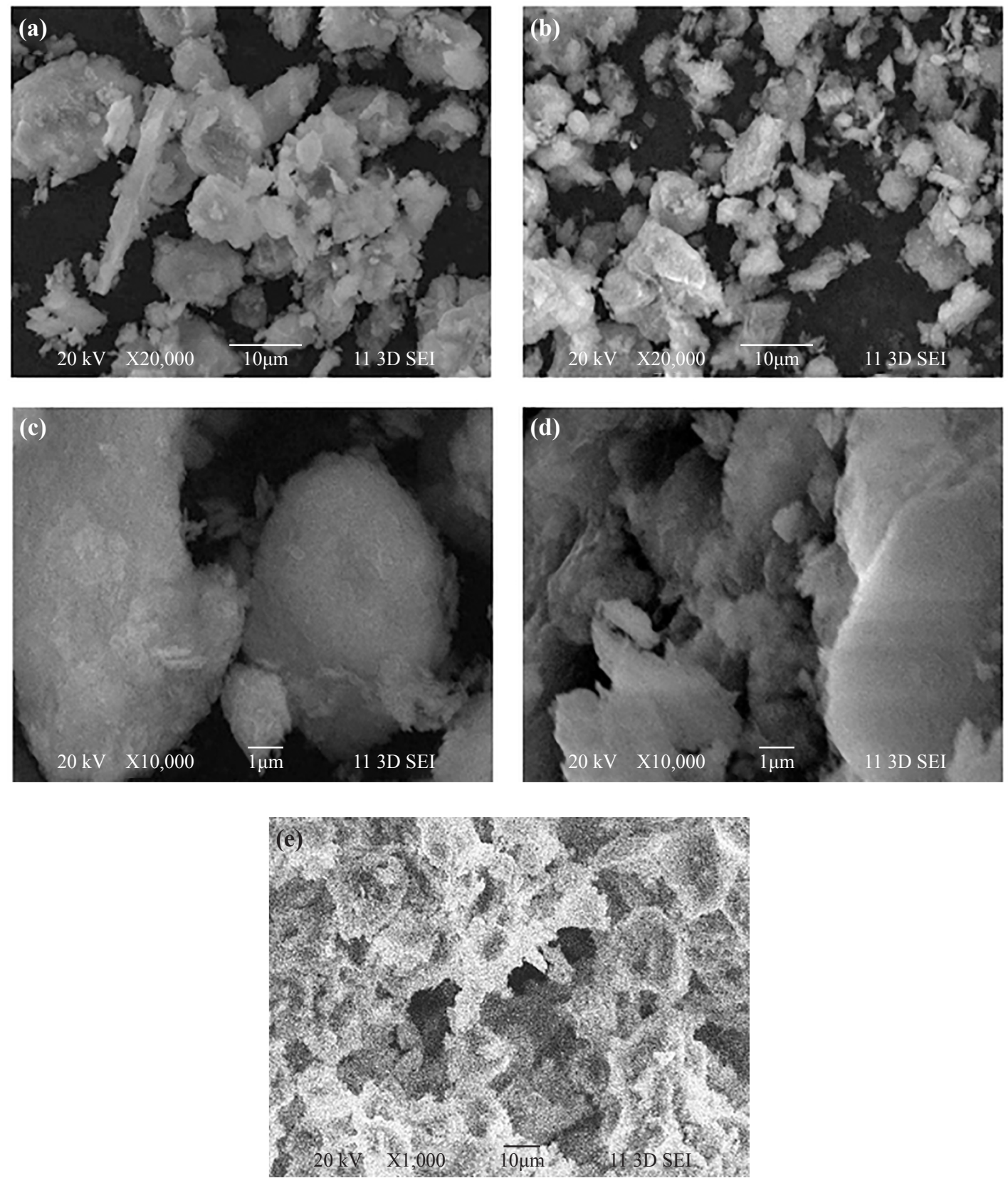

Figure 8. SEM images of ( $a, c)$ untreated and (b, d) treated clay at low and high magnifications respectively as well as (e) composite filter 2 
Figure 8 represents the scanning electron microscopic images (at low and high magnifications) of treated and untreated clay as well as an SEM image of a composite.

In the SEM images as shown in Figure $8(\mathrm{a}, \mathrm{b})$, it can be noticed that the particle's shape and size of treated and untreated clay are very similar. The particles have no definite shape. The particle sizes of both treated and untreated clay are in the range of 1-20 $\mu \mathrm{m}$. The particles surfaces of both treated and untreated clay appear smooth with some white shiny spots, which are visible in the higher magnified SEM image of untreated clay. It was expected that the surfaces of the modified clay would appear rough because of the grafting of tri-ethyl amine on the clay particles surfaces. However, the surface morphology of the original clay and modified clay are almost the same. Figure 8e represents an SEM image of nanocellulose dispersed modified clay composite containing $10 \mathrm{wt}$ \% nanocellulose. No agglomeration of nanocellulose was found in the SEM image of Figure 8e. Hence, the SEM analysis of composite indicated a good mixing of clay and nanocellulose.

\subsection{Removal of dye by the composites}

UV spectroscopy was used to determine the dye concentration in water before and after passing through the composite filter set in a column. The initial concentration of the dye in the wastewater was $250 \mathrm{mg} / \mathrm{L}$. Dye molecules present in the wastewater displayed a maximum value of absorbance of 0.56 at $520 \mathrm{~nm}$. Figure 9 represents a column diagram of the UV absorbance of the dye in wastewater and filtered water by different composite filters. In Figure 9, it is seen that dye was removed from wastewater by composite filter regardless of the compositions of the composite. Clay shows a strong attraction to both cationic and anionic dyes [52]. However, its adsorption capability for basic dyes is higher compared with acid dyes. The dye adsorption capacity of clay also depends on the net charges, pore sizes, and surface area of clay grains. In Figure 9, it is also noticed that dye was removed from wastewater by composite filter regardless of the compositions of the composite and the minimum dye adsorption capacity of the composite filters was $250 \mathrm{mg} / 5 \mathrm{~g}$, i.e., $50 \mathrm{mg} / \mathrm{g}$. This test indicated that dye is adsorbed on the clay and the effect of CNC in the composite filter was not distinguished.

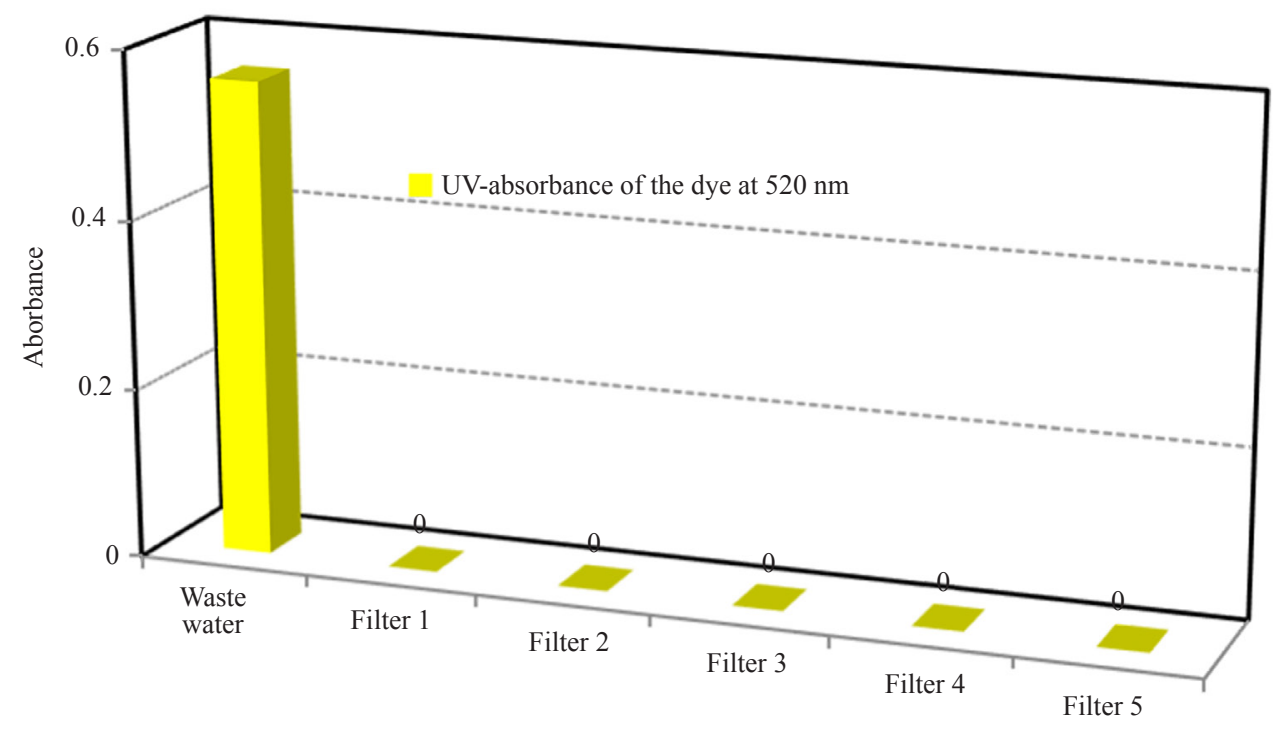

Figure 9. UV absorbance of the dye in the wastewater and filtered water by different composites

\subsection{Removal of heavy metal ions by the composites}

AAS was used to determine the content of the heavy metal ions namely $\mathrm{Pb}$ (II) and $\mathrm{Cr}$ (III) in the industrial wastewater samples before and after passing through the filter. Figure 10 displays the column diagram of $\mathrm{Pb}$ (II) and 
$\mathrm{Cr}$ (III) ions concentration in water before and after passing through the different composite filters. The labeling values at the top of the columns display the metal ions concentration in the water before and after passing through the filters. In Figure 10, it is obvious that both clay and $\mathrm{CNC}$ have adsorption capability to remove $\mathrm{Pb}$ (II) and $\mathrm{Cr}$ (III) ions from water. Plain clay is capable to adsorb about $76 \% \mathrm{~Pb}$ (II) from wastewater based on the initial concentration of $0.050 \mathrm{~g} /$ $\mathrm{L}$ of $\mathrm{Pb}$ (II) in water. The $\mathrm{Pb}(\mathrm{II})$ ion adsorption capability of clay becomes $100 \%$ by the dispersion of CNC in clay. From this analysis, it is obvious that the presence of $\mathrm{CNC}$ in the composite improved the $\mathrm{Pb}$ (II) ion adsorption capability of the composites and the minimum $\mathrm{Pb}$ (II) adsorption capacity of the composite filters was $50 \mathrm{mg} / 5 \mathrm{~g}$, i.e., $10 \mathrm{mg} /$ $\mathrm{g}$ when $\mathrm{CNC}$ content in the composites was $\geq 20 \mathrm{wt} . \%$. The higher lead ion removing capacity of the nanocellulose dispersed composite filter can be attributed to the lead ion removing capability of nanocellulose materials present in the composites. The capability of nanocellulose and modified nanocellulose for removing lead ions from the water was also reported by others [26], [53]. It was reported that the maximum $\mathrm{Pb}(\mathrm{II})$ ion adsorption capacities of nanocellulose and modified nanocellulose were $6.20 \mathrm{mg}$ and $186.5 \mathrm{mg}$ per gram of CNC [53].

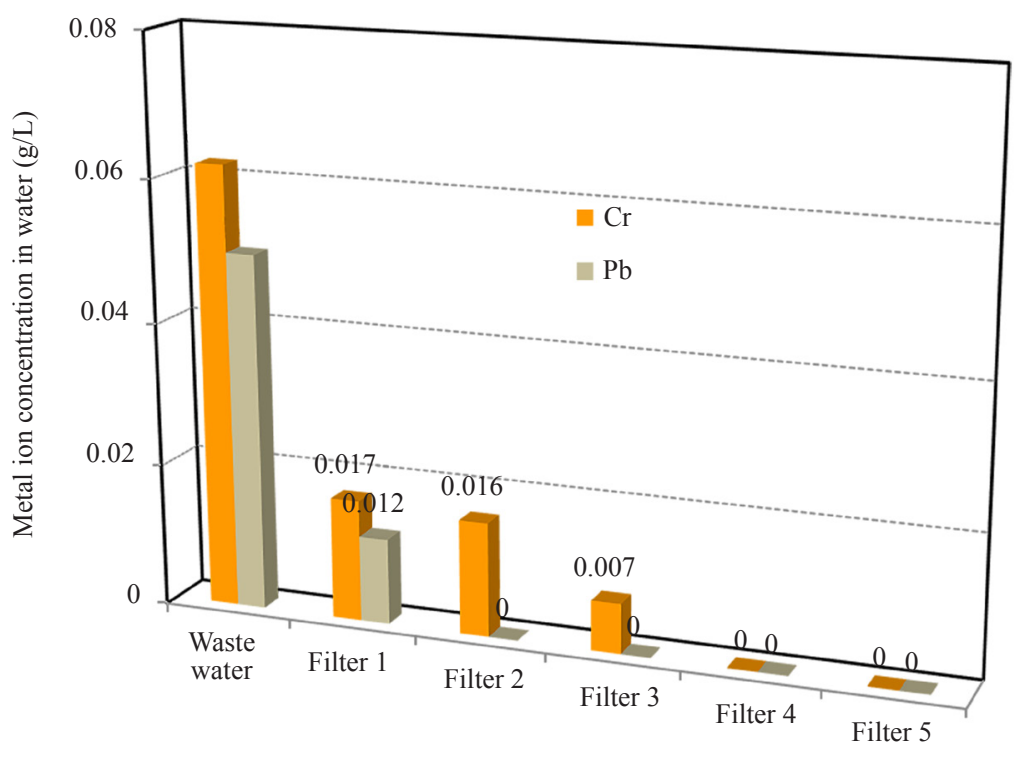

Figure 10. Metal ions concentration in water before and after passing through the different composite filters

In Figure 10, it is also obvious that plain clay is capable to adsorb about $72 \% \mathrm{Cr}$ (III) from wastewater based on the initial concentration of $0.062 \mathrm{~g} / \mathrm{L}$ of $\mathrm{Cr}(\mathrm{III})$ in water. $\mathrm{The} \mathrm{Cr}(\mathrm{III})$ ion adsorption capability of clay increased with increasing $\mathrm{CNC}$ content in the composite. When $\mathrm{CNC}$ content in the composite was $\geq 30 \mathrm{wt} \%$ then adsorption capability of the composite become $100 \%$. From this analysis, it is also obvious that the presence of CNC in the composite improved the $\mathrm{Cr}$ (III) ion adsorption capability of the composites and the minimum $\mathrm{Cr}$ (III) adsorption capacity of the composite filters was $62 \mathrm{mg} / 5 \mathrm{~g}$, i.e., $12.4 \mathrm{mg} / \mathrm{g}$ when CNC content in the composites is $\geq 30$ wt.\%. The improved performance of the nanocellulose dispersed composite filter can also be attributed to the heavy metal ions such as $\mathrm{Cr}$ (III) ions removing the capability of nanocellulose materials like lead ions. The capability of nanocellulose and modified nanocellulose for removing $\mathrm{Cr}$ (III) ions from wastewater was also reported in the literature [54]. It was reported that the $\mathrm{Cr}$ (III) ion adsorption capacities of nanocellulose and modified nanocellulose were $38.1 \mathrm{mg}$ and $47.0 \mathrm{mg}$ per gram of CNC [54]. From this investigation, it is also obvious that $\mathrm{Pb}(\mathrm{II})$ ions have more affinity to the prepared composite compared with $\mathrm{Cr}(\mathrm{III})$ ions.

\section{Conclusion}

A very simple and easy preparation of a composite filter based on banana rachis cellulose nanocrystals (CNCs) 
and clay has been reported. The prepared composite is highly capable of removing heavy metal ions namely $\mathrm{Pb}(\mathrm{II})$ and $\mathrm{Cr}$ (III) as well as dyes from industrial wastewater. The dye adsorption capacity of the composite filters was about 50 mg per gram of composite. And the $\mathrm{Pb}(\mathrm{II})$ and $\mathrm{Cr}$ (III) ions adsorption capacities of the composite filters were $>10.0$ $\mathrm{mg}$ and $>12.4 \mathrm{mg}$ respectively per gram of the composite when CNC content in the composite was $>30 \mathrm{wt} . \%$. In this study, the composite was prepared by a simple blending of CNC and clay. The CNC was obtained by the acid hydrolysis of cellulose obtained from banana rachis fibres. The clay collected from Bijoypur, Bangladesh was treated with triethyl amine. Both CNC and clay were characterized by FTIR, XRD, and SEM analyses. The performance of prepared composites of different compositions of CNC and clay was investigated by a UV-visible spectrophotometer and an atomic absorption spectrophotometer, respectively. It was found that the prepared composite filter was highly capable of adsorbing dye and heavy metals from industrial wastewater. It was also found that the metal ions adsorption capability of the composite filter was improved with increasing CNC content in the composites. Since clay is a very cheap raw material and kaolinite has no side effects and health problems if dust particles are controlled, the developed composite filter can be a very cost-effective and environmentally friendly adsorbent for removing dyes and heavy metals namely lead (II) and chromium (III) from industrial wastewater.

\section{Conflict of interest}

The authors declare that there is no conflict of interest regarding the publication of this paper.

\section{References}

[1] H. Babich, and G. Stotzky, "Heavy metal toxicity to microbe-mediated ecologic processes: a review and potential application to regulatory policies," Environmental research, vol. 36, no. 1, pp. 111-137, 1985.

[2] K. E. Giller, E. Witter, and S. P. Mcgrath, "Toxicity of heavy metals to microorganisms and microbial processes in agricultural soils: a review," Soil Biology and Biochemistry, vol. 30, no. 10-11, pp. 1389-1414, 1998.

[3] A. Ara, and J. A. Usmani, "Lead toxicity: a review," Interdisciplinary Toxicology, vol. 8, no. 2, pp. 55-64, 2015.

[4] H. P. Singh, P. Mahajan, S. Kaur, D. R. Batish, and R. K. Kohli, "Chromium toxicity and tolerance in plants," Environmental Chemistry Letters, vol. 11, no. 3, pp. 229-254, 2013.

[5] F. Baruthio, "Toxic effects of chromium and its compounds," Biological Trace Element Research, vol. 32, no. 1-3, pp. 145-153, 1992.

[6] J. F. Rosen, "Adverse health effects of lead at low exposure levels: trends in the management of childhood lead poisoning," Toxicology, vol. 97, no. 1-3, pp. 11-17, 1995.

[7] P. Nigam, G. Armour, I. M. Banat, D. Singh, and R. Marchant, "Physical removal of textile dyes from effluents and solid-state fermentation of dye-adsorbed agricultural residues," Bioresource Technology, vol. 72, no. 3, pp. 219226, 2000.

[8] M. Yusuf, "Synthetic dyes: a threat to the environment and water ecosystem," in Textiles and Clothing, 2019, pp. 11-26.

[9] E. Katsou, S. Malamis, T. Kosanovic, K. Souma, and K. J. Haralambous, "Application of adsorption and ultrafiltration processes for the pre-treatment of several industrial wastewater streams," Water, Air, \& Soil Pollution, vol. 223, no. 9, pp. 5519-5534, 2012.

[10] F. Fu, and Q. Wang, "Removal of heavy metal ions from wastewaters: a review," Journal of Environmental Management, vol. 92, no. 3, pp. 407-418, 2011.

[11] H. Borji, G. M. Ayoub, R. Bilbeisi, N. Nassar, and L. Malaeb, "How effective are nanomaterials for the removal of heavy metals from water and wastewater," Water, Air, \& Soil Pollution, vol. 231, no. 7, pp. 1-35, 2020.

[12] A. Pohl, "Removal of heavy metal ions from water and wastewaters by sulfur-containing precipitation agents," Water, Air, \& Soil Pollution, vol. 231, no. 10, pp. 1-17, 2020.

[13] B. O. Otunola, and O. O. Ololade, "A review on the application of clay minerals as heavy metal adsorbents for remediation purposes," Environmental Technology \& Innovation, vol. 18, pp. 100692, 2020.

[14] R. R. Chowreddy, K. Nord-Varhaug, and F. Rapp, "Recycled poly (ethylene terephthalate)/clay nanocomposites: rheology, thermal and mechanical properties," Journal of Polymers and the Environment, vol. 27, no. 1, pp. 37-49, 2019. 
[15] M. Rožić, Š. Cerjan-Stefanović, S. Kurajica, V. Vančina, and E. Hodžić, “Ammoniacal nitrogen removal from water by treatment with clays and zeolites," Water Research, vol. 34, no. 14, pp. 3675-3681, 2000.

[16] A. Lopez-Galindo, C. Viseras, and P. Cerezo, "Compositional, technical and safety specifications of clays to be used as pharmaceutical and cosmetic products," Applied Clay Science, vol. 36, no. 1-3, pp. 51-63, 2007.

[17] F. Uddin, "Clays, nanoclays, and montmorillonite minerals," Metallurgical and Materials Transactions A, vol. 39, no. 12, pp. 2804-2814, 2008.

[18] A. Mousharraf, M. S. Hossain, and M. F. Islam, "Potential of locally available clay as raw material for traditionalceramic manufacturing industries," Journal of Chemical Engineering, vol. 26, no. 1, pp. 34-37, 2011.

[19] J. W. Gruner, “The crystal structure of kaolinite," Zeitschrift für Kristallographie-Crystalline Materials, vol. 83, no. 1-6, pp. 75-88, 1932.

[20] G. W. Brindley, and K. Robinson, "The structure of kaolinite," Mineralogical Magazine and Journal of the Mineralogical Society, vol. 27, no. 194, pp. 242-253, 1946.

[21] P. M. Sanka, M. J. Rwiza, and K. M. Mtei, "Removal of selected heavy metal ions from industrial wastewater using rice and corn husk biochar," Water, Air, \& Soil Pollution, vol. 231, pp. 244, 2020.

[22] C. F. Mok, Y. C. Ching, F. Muhamad, N. A. Osman, N. Dai Hai, and C. R. Hassan, “Adsorption of dyes using poly (vinyl alcohol)(PVA) and PVA-based polymer composite adsorbents: a review," Journal of Polymers and the Environment, vol. 28, no. 6, pp. 775-793, 2020.

[23] S. K. Yong, N. Bolan, E. Lombi, and W. Skinner, "Synthesis and characterization of thiolated chitosan beads for removal of $\mathrm{Cu}$ (II) and Cd (II) from wastewater," Water, Air, \& Soil Pollution, vol. 224, no. 12, pp. $1720,2013$.

[24] R. Dhodapkar, N. N. Rao, S. P. Pande, and S. N. Kaul, "Removal of basic dyes from aqueous medium using a novel polymer: jalshakti,” Bioresource Technology, vol. 97, no. 7, pp. 877-885, 2006.

[25] J. H. Roque-Ruiz, E. A. Cabrera-Ontiveros, J. Torres-Pérez, and S. Y. Reyes-López, "Preparation of PCL/clay and PVA/clay electrospun fibers for cadmium $\left(\mathrm{Cd}^{+2}\right)$, chromium $\left(\mathrm{Cr}^{+3}\right)$, copper $\left(\mathrm{Cu}^{+2}\right)$ and lead $\left(\mathrm{Pb}^{+2}\right)$ removal from water," Water, Air, \& Soil Pollution, vol. 227, no. 8, pp. 286, 2016.

[26] A. Vázquez-Guerrero, R. Cortés-Martínez, R. Alfaro-Cuevas-Villanueva, E. M. Rivera-Muñoz, and R. HuiracheAcuña, "Cd (II) and $\mathrm{Pb}$ (II) adsorption using a composite obtained from moringa oleifera lam. Cellulose nanofibrils impregnated with ironnanoparticles," Water, vol. 13, no. 1, pp. 89, 2021.

[27] N. Tavker, V. K. Yadav, K. K. Yadav, M. Cabral-Pinto, J. Alam, A. K. Shukla, and M. Alhoshan, "Removal of cadmium and chromium by mixture of silver nanoparticles and nano-fibrillated cellulose isolated from waste peels of citrus sinensis," Polymers, vol. 13, no. 2, pp. 234, 2021.

[28] H. Yuan, J. Peng, T. Ren, Q. Luo, Y. Luo, N. Zhang, X. Guo, Y. Wu, and Y. Wu, "Novel fluorescent lignin-based hydrogel with cellulose nanofibers and carbon dots for highly efficient adsorption and detection of Cr (VI)," Science of the Total Environment, vol. 760, pp. 143395, 2021.

[29] M. Chen, B. Coasne, D. Derome, and J. Carmeliet, "Role of cellulose nanocrystals on hysteretic sorption and deformation of nanocomposites," Cellulose, vol. 27, pp. 6945-6960, 2020.

[30] M. C. Popescu, B. I. Dogaru, and C. M. Popescu, "Effect of cellulose nanocrystals nanofiller on the structure and sorption properties of carboxymethyl cellulose-glycerol-cellulose nanocrystals nanocomposite systems," Materials, vol. 13, no. 13, pp. 2900, 2020.

[31] L. Semerjian, "Removal of heavy metals $(\mathrm{Cu}, \mathrm{Pb})$ from aqueous solutions using pine (Pinus halepensis) sawdust: equilibrium, kinetic, and thermodynamic studies," Environmental Technology \& Innovation, vol. 12, pp. 91-103, 2018.

[32] H. E. Emam, and T. I. Shaheen, "Investigation into the role of surface modification of cellulose nanocrystals with succinic anhydride in dye removal," Journal of Polymers and the Environment, vol. 27, no. 11, pp. 2419-2427, 2019.

[33] K. A. Suman, M. Gera, and V. K. Jain, "A novel reusable nanocomposite for complete removal of dyes, heavy metals and microbial load from water based on nanocellulose and silver nano-embedded pebbles," Environmental Technology \& Innovation, vol. 36, no. 6, pp. 706-714, 2015.

[34] H. Ma, C. Burger, B. S. Hsiao, and B. Chu, "Nanofibrous microfiltration membrane based on cellulose nanowhiskers," Biomacromolecules, vol. 13, no. 1, pp. 180-186, 2012.

[35] M. M. Rahman, S. Afrin, P. Haque, M. Islam, M. S. Islam, and M. Gafur, "Preparation and characterization of jute cellulose crystals-reinforced poly (l-lactic acid) biocomposite for biomedical applications," International Journal of Chemical Engineering, vol. 2014, pp. 1-7, 2014.

[36] K. M. Mannan, and M. A. I. Talukder, "Characterization of raw, delignified and bleached jute fibres by study of absorption of moisture and some mechanical properties," Polymer, vol. 38, no. 10, pp. 2493-2500, 1997.

[37] M. M. Rahman, M. Maniruzzaman, M. R. Islam, and M. S. Rahman, "Synthesis of nano-cellulose from okra fibre 
and ftir as well as morphological studies on it," American Journal of Polymer Science and Technology, vol. 4, no. 2, pp. 42-52, 2018.

[38] W. Li, L. Yu, G. Liu, J. Tan, S. Liu, and D. Sun, “Oil-in-water emulsions stabilized by Laponite particles modified with short-chain aliphatic amines," Colloids and Surfaces A: Physicochemical and Engineering Aspects, vol. 400, pp. 44-51, 2012.

[39] R. Bhaskar, J. Li, and L. Xu, “A comparative study of particle size dependency of IR and XRD methods for quartz analysis," American Industrial Hygiene Association Journal, vol. 55, no. 7, pp. 605-609, 1994.

[40] S. Ifuku, M. Tsuji, M. Morimoto, H. Saimoto, and H. Yano, "Synthesis of silver nanoparticles templated by TEMPO-mediated oxidized bacterial cellulose nanofibers," Biomacromolecules, vol. 10, no. 9, pp. 2714-2717, 2009.

[41] H. Yang, R. Yan, H. Chen, D. H. Lee, and C. Zheng, "Characteristics of hemicellulose, cellulose and lignin pyrolysis," Fuel, vol. 86, no. 12-13, pp. 1781-1788, 2007.

[42] M. M. Islam, M. N. Khan, S. Biswas, T. R. Choudhury, P. Haque, T. U. Rashid, and M. M. Rahman, "Preparation and characterization of bijoypur clay-crystalline cellulose composite for application as an adsorbent," Advanced Material Science, vol. 2, pp. 1-7, 2017.

[43] N. J. Saikia, D. J. Bharali, P. Sengupta, D. Bordoloi, R. L. Goswamee, P. C. Saikia, and P. C. Borthakur, "Characterization, beneficiation and utilization of a kaolinite clay from Assam, India," Applied Clay Science, vol. 24, no. 1-2, pp. 93-103, 2003.

[44] P. S. Nayak, and B. K. Singh, "Instrumental characterization of clay by XRF, XRD and FTIR," Bulletin of Materials Science, vol. 30, no. 3, pp. 235-238, 2007.

[45] J. Madejova, J. Kečkéš, H. Pálková, and P. Komadel, "Identification of components in smectite/kaolinite mixtures," Clay Minerals, vol. 37, no. 2, pp. 377-388, 2002.

[46] M. Klinkenberg, R. Dohrmann, S. Kaufhold, and H. Stanje, "A new method for identifying wyoming bentonite by ATR-FTIR,” Applied Clay Science, vol. 33, no. 3-4, pp. 195-206, 2006.

[47] V. Krishnamurthy, I. L. Kamel, and Y. Wei, “Analysis of plasma polymerization of allylamine by FTIR," Journal of Polymer Science Part A: Polymer Chemistry, vol. 27, no. 4, pp. 1211-1224, 1989.

[48] S. Ouajai, and R. A. Shanks, "Composition, structure and thermal degradation of hemp cellulose after chemical treatments," Polymer Degradation and Stability, vol. 89, no. 2, pp. 327-335, 2005.

[49] A. El Oudiani, Y. Chaabouni, S. Msahli, and F. Sakli, "Crystal transition from cellulose I to cellulose II in NaOH treated Agave americana L. fibre," Carbohydrate Polymers, vol. 86, no. 3, pp. 1221-1229, 2011.

[50] E. Abraham, B. Deepa, L. A. Pothan, M. Jacob, S. Thomas, U. Cvelbar, and R. Anandjiwala, "Extraction of nanocellulose fibrils from lignocellulosic fibres: a novel approach," Carbohydrate Polymers, vol. 86, no. 4, pp. 1468-1475, 2011.

[51] Perel J, “An X-ray study of regain-dependent deformations in cotton crystallites," Journal of the Textile Institute, vol. 81, no. 3, pp. 241-244, 1990.

[52] S. C. Santos, and R. A. Boaventura, "Adsorption of cationic and anionic azo dyes on sepiolite clay: equilibrium and kinetic studies in batch mode," Journal of Environmental Chemical Engineering, vol. 4, no. 2, pp. 1473-1483, 2016.

[53] T. Suopajärvi, H. Liimatainen, M. Karjalainen, H. Upola, and J. Niinimäki, "Lead adsorption with sulfonated wheat pulp nanocelluloses," Journal of water process engineering, vol. 5, pp. 136-142, 2015.

[54] P. Jain, S. Varshney, and S. Srivastava, "Synthetically modified nano-cellulose for the removal of chromium: a green nanotech perspective," IET Nanobiotechnology, vol. 11, no. 1, pp. 45-51, 2016. 